\title{
The Dual Role of Mannitol as Osmoprotectant and Photoassimilate in Celery
}

\author{
D.M. Pharr ${ }^{1}$, J.M.H. Stoop ${ }^{2}$, J.D. Williamson ${ }^{3}$, M.E. Studer Feusi ${ }^{2}$, M.O. Massel ${ }^{4}$, and M.A. Conkling ${ }^{5}$ \\ North Carolina State University, Box 7609, Raleigh, NC 27695-7609
}

\begin{abstract}
Mannitol, a six carbon noncyclic sugar alcohol, is the most abundant polyol in nature, occurring in bacteria, fungi, algae, lichens, and in at least 70 species of vascular plants (Bieleski, 1982; Lewis, 1984). Various roles have been postulated for mannitol in these organisms, including carbon storage, free radical scavenging, osmoregulation, and service as a compatible solute (Bieleski, 1982; Loescher, 1987). Some of these roles are of obvious importance in stress tolerance, particularly in tolerance to salt stress, which invariably causes osmostress of varying durations in plants. Mannitol is also a phloemtranslocated photoassimilate in some vascular plants (Bieleski, 1982; Loescher, 1987). This article focuses on the enzymatic synthesis and degradation of mannitol in celery (Apium graveolens L. var. dulce) plants and the role of these pathways in controlling mannitol accumulation in stressed plants.
\end{abstract}

\section{BIOCHEMISTRY OF MANNITOL SYNTHESIS AND CATABOLISM}

\section{Mannitol synthesis}

In celery plants, mannitol is a major product of leaf photosynthesis and constitutes as much as $50 \%$ of the phloem-translocated photoassimilate (Loescher et al., 1992). The remainder of the translocated photoassimilate is largely sucrose. The partitioning of photosynthetically fixed $\mathrm{CO}_{2}$ between mannitol and sucrose (Fig. 1) is a function of leaf age, with mannitol favored in more mature leaves (Davis et al., 1988). The biosynthetic pathway of mannitol from photosynthetic intermediates was first described in celery in the early 1980s (Rumpho et al., 1983). More recently, the pathway also was demonstrated in privet (Ligustrum vulgare L.) (Loescher et al., 1992). Mannitol is formed in the cytosol of photosynthetic leaf cells by the NADPH-dependent reduction of mannose-6-P to mannitol-1-P, constituting a reduction of carbon-1. The subsequent removal of $\mathrm{Pi}$ from mannitol-1-P by a phosphatase produces mannitol. Sucrose and mannitol biosynthesis share common intermediates originating from triose phosphates exported from chloroplasts and leading to the production of fructose-6-P (Fig. 1). In lower organisms, such as bacteria, yeast, and algae, mannitol is formed by the reduction of carbon- 2 in fructose or fructose-6-P to form mannitol or mannitol-1-P, respectively. Thus, vascular plants synthesize mannitol by a different set of enzymatic reactions than other organisms.

The enzyme catalyzing the reduction of mannose-6-P to mannitol1-P, mannose-6-P reductase (M-6-PR), was purified to homogeneity from celery (Loescher et al., 1992). The molecular mass of the native enzyme was estimated, by physical methods, to be about $58 \mathrm{kD}$. The molecular mass of the monomer, as determined by sodium dodecyl sulfate (SDS) gel electrophoresis, was $35 \mathrm{kD}$, leading to the conclusion

Received for publication 17 Mar. 1995. Accepted for publication 8 Apr. 1995. This work was supported in part by the North Carolina Agricultural Research Service Raleigh, NC 27695; U.S. Dept. of Agriculture Competitive Grant no. 9302250; the Belgian American Educational Foundation (J.M.H. Stoop); and the Swiss National Foundation (M.E. Studer Feusi). Use of trade names does not imply endorsement of the products named nor criticism of similar ones not named. The cost of publishing this paper was defrayed in part by the payment of page charges. Under postal regulations, this paper therefore must be hereby marked advertisement solely to indicate this fact.

${ }^{1}$ Professor, Dept. of Horticultural Science.

${ }^{2}$ Postdoctoral Research Associate, Dept. of Horticultural Science.

${ }^{3}$ Visiting Assistant Professor, Dept. of Horticultural Science.

${ }^{4}$ Laboratory Research Technician, Dept. of Horticultural Science.

${ }^{5}$ Associate Professor, Dept. of Genetics. that the native enzyme was probably a dimer. Polyclonal antibodies raised against the enzyme were used in immunocytochemical studies demonstrating that M-6-PR was located in the cytosol of photosynthetic mesophyll cells, as depicted in the model (Fig. 1) (Everard et al., 1993a). This result confirmed an earlier conclusion concerning the location of this enzyme based on cell fractionation studies (Rumpho et al., 1983) and clearly implies the need for a massive quantity of NADPH in the cytosol of the mesophyll cells during mannitol biosynthesis. This requirement for cytosolic reductant in mannitol-forming plants poses an interesting problem in that photochemically produced NADPH is generated exclusively within the chloroplast, and NADPH cannot pass directly through the chloroplast membranes into the cytosol. NADPH is supplied indirectly by shuttling another metabolite generated within the chloroplast to the cytosol (Fig. 1). Subsequent to the photosynthetic reduction of 3-PGA to triose phosphate within the chloroplast, triose phosphate is exported to the cytosol in exchange for 3-PGA. The triose-phosphate is oxidized in the cytosol to 3-PGA by a nonreversible triose-phosphate dehydrogenase, generating NADPH from NADP. The resulting NADPH then can be used for the reductive step in mannitol synthesis. Nonreversible cytosolic triose-phosphate dehydrogenase activity is present at as much as five times higher activity in extracts of celery leaves than in extracts from leaves of plants that exclusively form sucrose as the photosynthetic export product (Rumpho et al., 1983). The overall result of this metabolite shuttle, providing for NADP reduction in the cytosol, is a transfer of reducing equivalents to the cytosol from the chloroplasts with no net gain or loss of $\mathrm{C}$ or phosphate within the cytosol or chloroplasts.

\section{Mannitol catabolism}

Carbon derived from translocated products of photosynthesis is used in nonphotosynthetic (sink) tissues as a storage reserve for later use or in the immediate production of energy and carbon skeletons for synthetic reactions to build cellular components (Fig. 2). This scheme is a critical aspect of growth in all plants, as assimilation of translocated photosynthates is the only means of $\mathrm{C}$ gain in nonphotosynthetic tissues. In celery, radioactively labeled sucrose supplied to excised tissues is readily converted to $\mathrm{CO}_{2}$, whereas the conversion of mannitol to $\mathrm{CO}_{2}$ is largely restricted to actively growing sinks (Fellman and Loescher, 1987). Petioles of celery contain a substantial storage pool of mannitol, with $\approx 80 \%$ of the mannitol being in vacuoles of the petiole storage parenchyma cells and the remainder in the cytosol (Keller and Matile, 1989). Activity of the mannitol synthetic enzyme, M-6-PR, is extremely low in petiole parenchyma tissue, supporting the hypothesis that mannitol is accumulated from the phloem translocation stream (Keller and Matile, 1989).

The initial enzymatic step by which mannitol enters the central metabolism in sink tissues of vascular plants was only recently discovered. A mannitol-oxidizing enzyme, NAD-dependent mannitol:mannose 1-oxidoreductase, was identified in celeriac [Apium graveolens var. rapaceum (Mill.) Gandich.] plants and subsequently in celery (Stoop and Pharr, 1992). Unlike M-6-PR, mannitol dehydrogenase (MDH) is not active in photosynthetic leaves. MDH occurs only in actively growing sink tissues of celery and celeriac plants, and the enzyme is absent or barely detectable in photosynthetic leaves and mature petioles that store mannitol. Distribution of MDH activity throughout celery plants (Stoop and Pharr, 1992) mirrors the previously reported capacity of the tissues to convert mannitol to $\mathrm{CO}_{2}$ (Fellman and Loescher, 1987). Additionally, the activity of the enzyme in various tissues of the plant is inversely correlated with tissue mannitol concentration (Stoop and Pharr, 1992). Collectively, these observations strongly suggest a role for $\mathrm{MDH}$ in mannitol catabolism. 


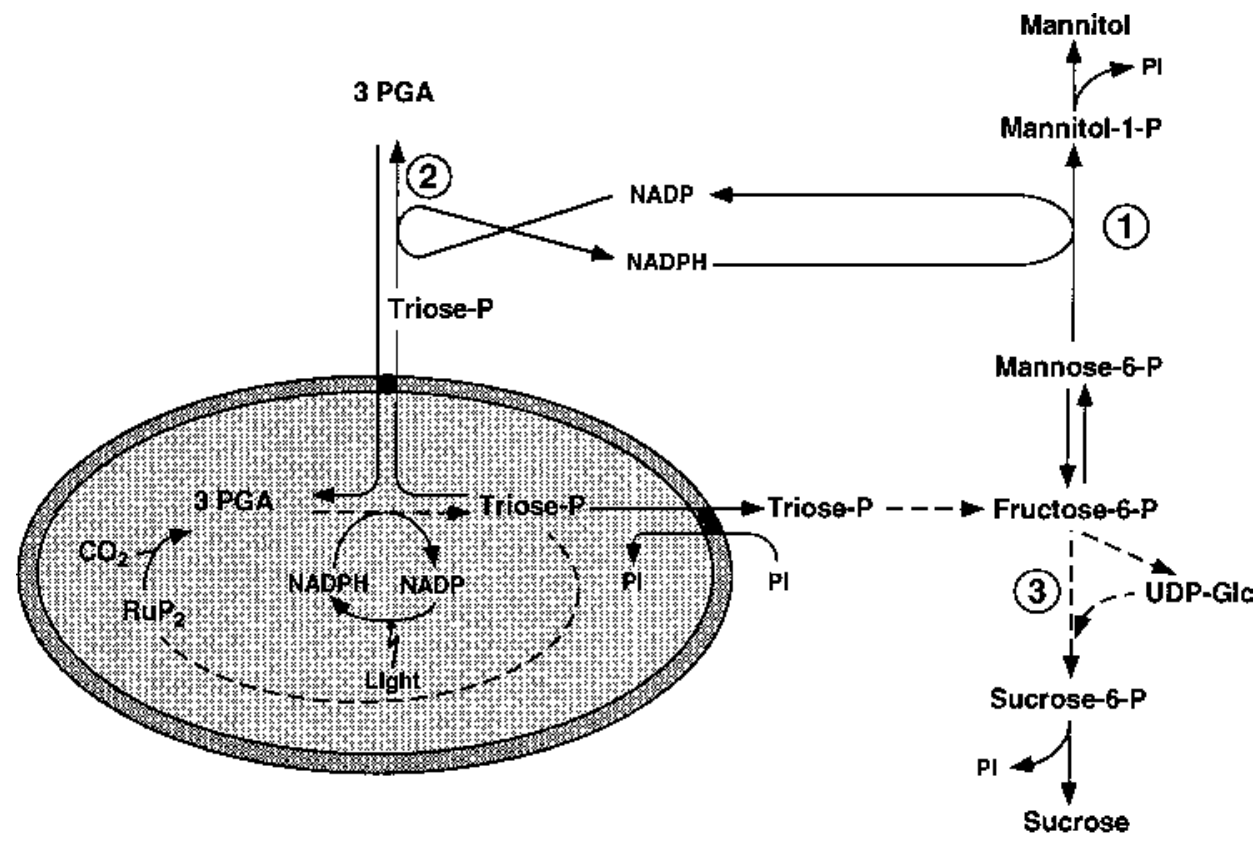

CHLOROPLAST

CYTOSOL

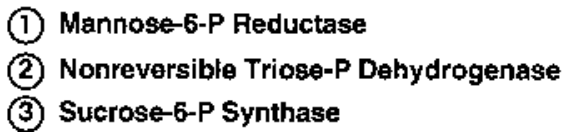

Fig. 1. Simplified scheme showing the biosynthesis of mannitol from photosynthetically fixed $\mathrm{CO}_{2}$.

The celery MDH is unlike mannitol dehydrogenases found in lower organisms. The latter enzymes are all 2-oxidoreductases that catalyze oxidation of mannitol or mannitol-1-P at carbon-2 to form fructose or fructose-6-P as a product. The enzyme from celery and celeriac is a 1-oxidoreductase that catalyzes the oxidation of mannitol at carbon- 1 to form mannose. NAD functions as the electron acceptor while NADP does not. A somewhat analogous mannitol-oxidizing enzyme that attacks carbon-1 was isolated from mitochondria of the land snail (Helix aspersa Miller); however, the snail enzyme does not depend on pyridine nucleotide as a cosubstrate (Vorhaben et al., 1980). Aside from the single report in celery and celeriac, there is apparently no precedent for the existence of a NAD-dependent mannitol 1oxidoreductase. It will be of interest to learn if the occurrence of this particular type of mannitol dehydrogenase is restricted to vascular plants. Recently, our laboratory has isolated highly purified MDH from mannitol-grown celery suspension culture. Unlike the biosynthetic enzyme, MDH is apparently a monomer. Molecular size of the native enzyme as estimated by gel filtration chromatography was $\approx 52$ $\mathrm{kD}$. The denatured protein runs as a single $46-\mathrm{kD}$ band on SDS gels (unpublished). Polyclonal antibodies raised against the SDS-denatured peptide are cross-reactive with the enzyme from celery plants.

In celery, mannose derived from the oxidation of mannitol subsequently is phosphorylated at carbon- 6 by hexokinase to form mannose-6-P, which in turn can be isomerized by phosphomannose isomerase (PMI) to fructose-6-P (Stoop and Pharr, 1992, 1993, 1994a). Fructose-6-P is a central metabolite that can be used in the formation of many important compounds for growth and respiratory energy production (Fig. 2). Extracts of celery contain relatively high levels of PMI (Stoop and Pharr, 1992, 1993, 1994a). This enzyme is critical for the use of mannose as a $\mathrm{C}$ source. Certain plants are incapable of rapidly metabolizing exogenously supplied mannose, probably due to their lack of sufficiently high levels of PMI (Herold and Lewis, 1977). In these species, mannose is toxic, apparently due to the accumulation of mannose-6-P with the resulting sequestration of cellular phosphate (Herald and Lewis, 1977). Cell suspension cultures of celery grow

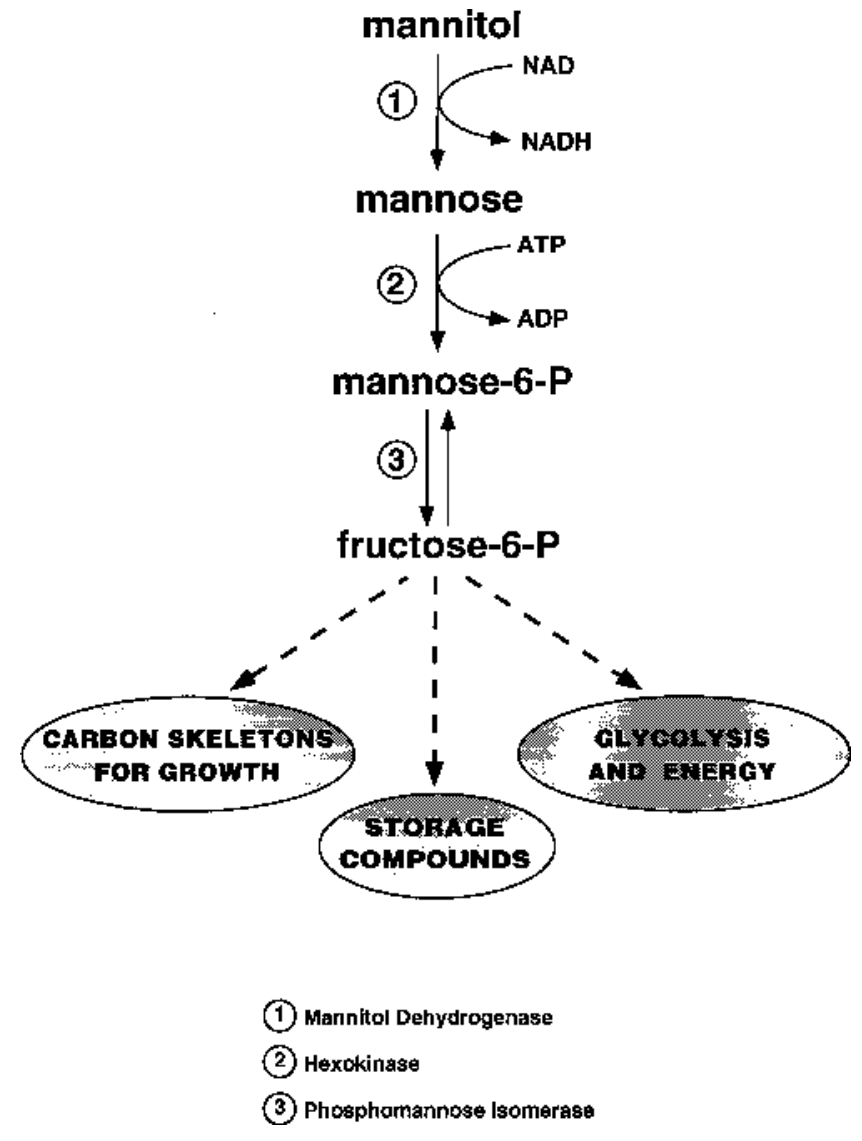

Fig. 2. Simplified scheme depicting the assimilation of mannitol in nonphotosynthetic sink tissues, starting with its oxidation to mannose. 
readily on mannose, strongly supporting the notion that this species is biochemically well adapted to metabolize mannose, the product of mannitol oxidation (Stoop and Pharr, 1993).

\section{MANNITOL AS A TRANSLOCATED PHOTOASSIMILATE}

\section{Mannitol synthesis and high photosynthetic rates}

Celery has exceptionally high photosynthetic rates for a C-3 plant, as high as $60 \mathrm{mg} \mathrm{CO} / \mathrm{dm}^{2}$ per hour in some leaves (Fox et al., 1986). As is true for other species, $\mathrm{CO}_{2}$ fixation rates vary with leaf maturity (Fox et al., 1986). These high rates in celery leaves could be related to the massive turnover of NADPH in the cytosol of the mesophyll cells during the reduction of mannose-6-P to mannitol-1-P (Fox et al., 1986; Loescher, 1987). The reduction of mannose-6-P during mannitol biosynthesis serves as a ready outlet for photochemically produced reductant supplied indirectly in the manner described previously. Rather than being viewed as an energy consumptive step in the synthesis of translocated photoassimilate, mannitol biosynthesis should be viewed as a biochemical adaptation that in effect extends the carbon reduction reactions of photosynthesis into the cytosol, constituting an additional step for the capture of photochemical energy. This adaptation may be an important factor contributing to the high photosynthetic rates in celery because reductant may be produced more rapidly than it can be used for $\mathrm{C}$ reduction within chloroplasts of C-3 plants (Stitt, 1986). However, this increased ability by mannitol-forming plants to use excess photochemically produced reductant cannot be the sole cause of high photosynthetic rates. As mentioned, the reductant shuttle does not result in net export of $\mathrm{C}$ to the cytosol and, therefore, in itself does not result in increased $\mathrm{CO}_{2}$ fixation. For enhanced photosynthetic rates, it is important to recognize that mannitol represents another $\mathrm{C}$ sink in addition to sucrose, thus increasing the outlets in the cytosol for $\mathrm{C}$ exported from the chloroplasts and ultimately from the leaf. Therefore, high photosynthetic rates may be an intrinsic advantage in the biochemistry of plants that form large quantities of mannitol in addition to sucrose as photosynthetic products.

\section{Mannitol and efficient sink metabolism}

The high capacity to capture energy in reduced chemical form at the photosynthetic source, leaves, may be only one of the advantages of using mannitol as a translocated photoassimilate. Because mannitol is more highly chemically reduced (i.e., an alcohol) than sucrose (i.e., comprised of an aldose and ketose), the complete oxidation of mannitol yields more energy per mole than analogous aldoses and ketoses. Some apparent advantages of mannitol vs. sucrose catabolism in sink tissues have been discussed by Stoop and Pharr (1992) and are summarized here. Catabolism of sucrose in sink cells may involve hydrolysis catalyzed by invertases. In this case, two ATPs are required to phosphorylate the resulting glucose and fructose moieties before their entry into central metabolism. In sucrose degradation by sucrose synthase, energy is conserved in the form of UDP-glucose, and thus only one ATP is required to phosphorylate the resulting fructose before its entry into central metabolism. In either case, the initial steps of sucrose metabolism in sink cells require an input of ATP. In mannitol catabolism, the initial oxidative step generates a net yield of one NADH for each mannitol oxidized (Fig. 2). Mitochondrial oxidation of the NADH gives a theoretical yield of three ATPs with only one of these required to phosphorylate mannose before its conversion to fructose-6-P (Fig. 2). Thus, hexose-P generated from mannitol in sink cells is accompanied by the net generation of two ATPs per mannitol converted. In contrast, the initial generation of hexose-P from sucrose in sink cells occurs at the expense of ATP. From these biochemical considerations, we hypothesize that sink cells with the capacity for both mannitol and sucrose catabolism would grow more efficiently on mannitol than on sucrose.

This hypothesis was addressed in our laboratory through experiments using celery cells growing heterotropically in suspension cultures. Efficiency of $\mathrm{C}$ source use was assessed by measuring the gain in cell dry weight and depletion of medium carbohydrates during several culture cycles. Celery cells grew on either sucrose or manni- tol as the only C source in the suspension culture medium (Stoop and Pharr, 1993). Typical cell growth (milliliters of cells per milliliters of medium) and culture medium carbohydrate depletion data are shown in Fig. $3 \mathrm{~A}$ and B. In the case of sucrose, considerable extracellular hydrolysis of sucrose occurred during the culture cycle, and the carbohydrate depletion data (Fig. 3B) are the sum of sucrose, glucose, and fructose, representing total $\mathrm{C}$ source depletion for sucrosegrown cells. From such data, the medium carbohydrate concentration was regressed against cell dry weights at various times after culture initiation and throughout the logarithmic growth of the cultures. Data from eight individual growth cycles for mannitol and sucrose-grown celery cells were used to construct the relationships in Figs. $3 \mathrm{C}$ and D. From the slopes of these regressions, the average consumption of $2.93 \mathrm{mg}$ of mannitol occurred for each milligram increase in cell dry weight (Fig. 3C), whereas $3.72 \mathrm{mg}$ of sucrose was consumed for each milligram increase in cell dry weight (Fig. 3D). Thus, for celery cells, the conversion of mannitol to cell dry weight was $\approx 27 \%$ more efficient than the conversion of sucrose. This advantage in efficiency of assimilation may be due to energetics inherent in the initial steps of catabolism of mannitol vs. sucrose, such that there is less need for respiratory use of mannitol than for sucrose in sinks. While there is no specific evidence that growth of sink cells within intact celery plants is higher per unit weight of mannitol assimilated than per unit weight of sucrose assimilated, the data above for cultured cells suggest that such a difference is possible. If so, this constitutes another advantage of mannitol over sucrose as a translocated photoassimilate.

\section{MANNITOL AS AN OSMOTICALLY ACTIVE STRESS METABOLITE}

\section{Mannitol as an osmolyte in nonvascular plants}

In nonvascular organisms, such as algae and fungi, and in vascular plants, polyols accumulate in response to environmental stresses and can act as osmolytes, compatible solutes, or both (Jennings, 1984; Kirst, 1989). Compatible solutes may accumulate in the cytosol where they prevent inactivation of metabolic processes (Greenway and Munns, 1980). Schobert (1977) suggested that polyols can perform this function because their water-like $\mathrm{OH}$ groups may mimic the structure of water and maintain an artificial sphere of "hydration" around the macromolecule. Compatible solutes also may function as scavengers of membrane-damaging hydroxyl radicals generated during stress (Smirnoff and Cumbes, 1989).

In the marine alga, Platymonas subcordiformis (Wille) Hazen, mannitol is the main photosynthetic product and accumulates at increased levels in response to hyperosmotic conditions (Richter and Kirst, 1987). Additions of up to $800 \mathrm{~mm} \mathrm{NaCl}$ to an in vitro enzymatic assay resulted in a progressive inhibition of NAD-dependent mannitol dehydrogenase, the mannitol-catabolizing enzyme, while NADdependent mannitol-1-P dehydrogenase, the mannitol-synthesizing enzyme, exhibited progressively increasing activity over the same range of salt concentrations (Richter and Kirst, 1987). This pattern indicates that the mannitol pool in these organisms is not only regulated by increased amounts of synthetic or catabolic proteins, but also by altered activity of the existing enzymes. Osmotic adjustment in algae seems to be regulated by a coordinated process between ionic and organic solutes (Kirst, 1989). Microalgae exposed to a hyperosmotic stress rapidly increased ion concentrations during the first hour of exposure, followed by a decrease, which was in turn followed by an increase in glycerol or mannitol (Kirst, 1989 and references therein).

\section{Mannitol and salt tolerance in vascular plants and cells}

Tobacco (Nicotiana tabacum L.), a plant that normally does not contain detectable concentrations of mannitol, was recently metabolically engineered to produce mannitol. Remarkably, this was accomplished by introducing a single gene from Escherichia coli under the control of the $35 \mathrm{~S}$ cauliflower mosaic virus promoter (Tarczynski et al., 1992). The gene $m t l D$ encodes mannitol-1-P 

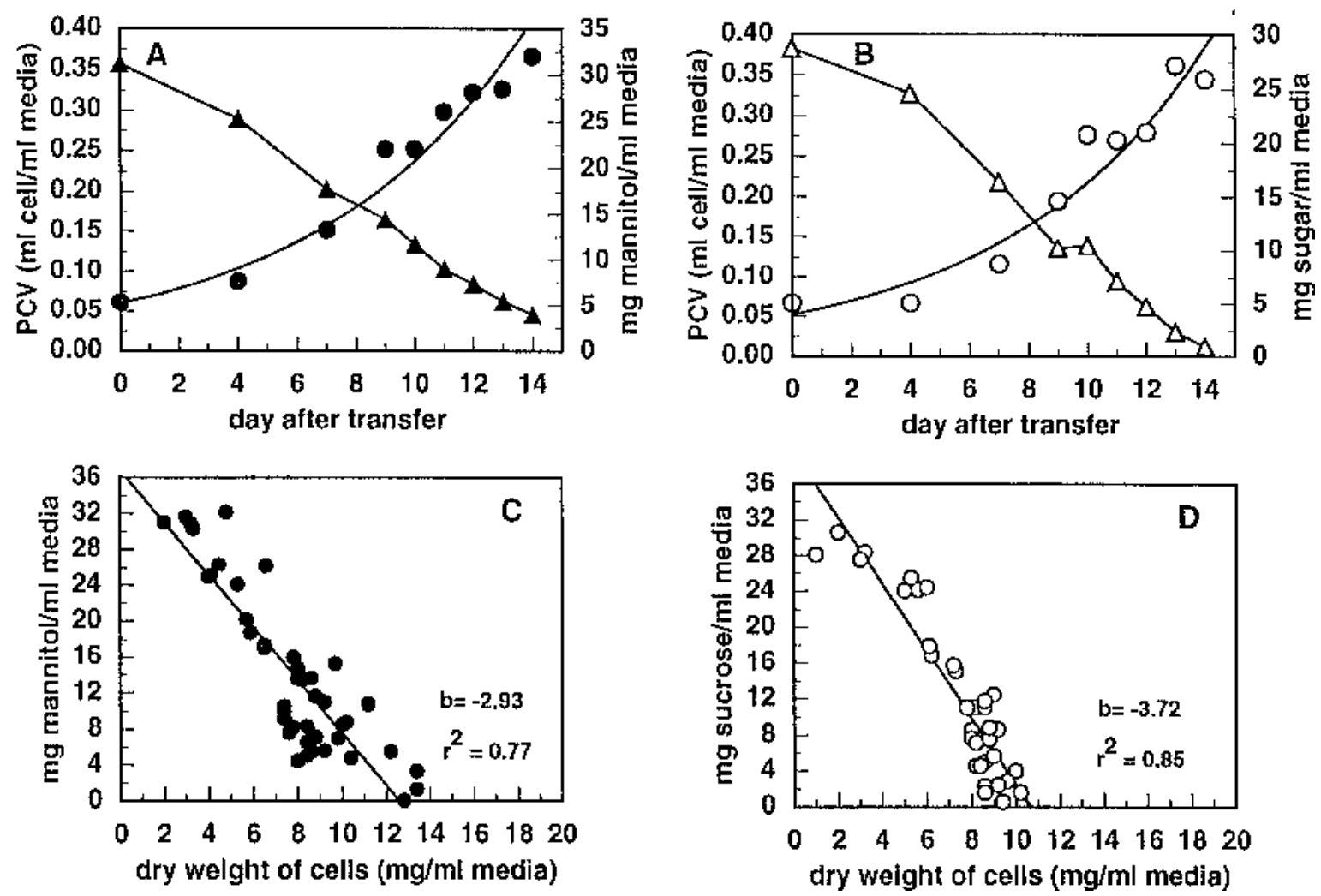

Fig. 3. Typical growth $(\mathbf{O}, \bigcirc)$ and medium carbohydrate $(\mathbf{A}, \Delta)$ depletion patterns for celery suspension cultures growing on either $(\mathbf{A})$ mannitol or $(\mathbf{B})$ sucrose as the sole $\mathrm{C}$ source. Correlations between dry weight of cells produced during the culture cycle and the concentration of $\mathrm{C}$ source $(\mathbf{C})$ mannitol and (D) sucrose in the medium. Slopes of the regressions are used to determine the efficiency of conversion of growth substrates to cell dry weight. Slopes of the regression in $(\mathbf{C})$ and $(\mathbf{D})$ were statistically different at $P=0.05$. See text for discussion. PCV $=$ packed cell volume.

dehydrogenase, an enzyme that catalyzes the reversible reduction of fructose-6-P to mannitol-1-P and uses NADH as the electron donor and NAD as the electron acceptor. Plants transformed with the E. coli $m t l D$ gene expressed the mannitol-1-P dehydrogenase enzyme and accumulated mannitol throughout the plant. The authors postulated that mannitol-1-P was formed from fructose-6-P, giving rise to mannitol through the action of a nonspecific phosphatase already present in tobacco.

Interestingly, Tarczynski et al. (1993) demonstrated that the mannitol-accumulating, transformed tobacco exhibited greater salt tolerance than nontransformed tobacco. Growth of the nontransformed tobacco, in the presence of $250 \mathrm{~mm} \mathrm{NaCl}$ in hydroponic nutrient culture, was strongly reduced compared to that of transformed mannitol-containing tobacco. These experiments clearly and unequivocally establish that mannitol can promote salt tolerance in higher plants, but the mechanism(s) by which this occurs is(are) not yet known. For example, whether mannitol concentration increases in salt-stressed transgenetic tobacco countering osmotic stress or if altered compartmentation of mannitol occurs between the cytosol and the vacuole in response to salt stress remains unknown. Other protective mechanisms also may be involved.

Some hypotheses suggest that plant growth is inhibited indirectly by salt stress through the effects on photosynthesis and assimilate supply. Certain deficiencies in these hypotheses were discussed in a review by Munns (1993). For example, inhibition of growth often precedes inhibition of photosynthesis. Interestingly, mannitol can function to provide salt tolerance in nonphotosynthetic cultured celery cells. Growth of celery cells in suspension cultures with sucrose as the sole $\mathrm{C}$ source was inhibited $50 \%$ in the presence of $170 \mathrm{~mm} \mathrm{NaCl}$. In comparison, in mannitol-grown cells, $50 \%$ inhibition occurred at 320 $\mathrm{mm} \mathrm{NaCl}$ (Stoop, 1993). Enhanced salt tolerance of celery cells growing on mixtures of sucrose and mannitol also was observed relative to sucrose-grown cells. Thus, tissue organization and wholeplant structure is not required for at least some of the beneficial effects of mannitol in ameliorating growth-inhibiting effects of salt stress in higher plant cells.

\section{Regulation of mannitol pool in celery plants during salt and osmostress}

Cultivated celery was developed from an ancestral plant (Apium graveolens $\mathrm{L}$. var. silvestre) native to coastal habitats of Europe, North Africa, and Asia and is a likely candidate to exhibit salt tolerance (Yamaguchi, 1983). Several recent reports suggest that celery exhibits significant tolerance to salinity, and this tolerance may be related to the fact that celery contains mannitol and has the ability to accumulate additional mannitol in response to salinity and osmostress (Everard et al., 1994; Kann et al., 1993; Stoop and Pharr, 1994b). Everard et al. (1992) demonstrated that $100 \mathrm{~mm} \mathrm{NaCl}$ did not affect growth of celery plants, but $300 \mathrm{~mm}$ was strongly inhibitory. Young leaves and the crown of celery plants remained viable after exposure to $500 \mathrm{~mm} \mathrm{NaCl}$ in the root environment for up to 2 weeks, as was evident from the resumption of growth after the salt was leached from the pots in which the plants were growing. This survival constitutes strong salt tolerance in that $500 \mathrm{~mm} \mathrm{NaCl}$, i.e., electrical conductivity (EC) of $42 \mathrm{dS} \cdot \mathrm{m}^{-1}$, is roughly equivalent to the salinity of seawater (Clipson et al., 1990). Mannitol increased in concentration in shoots and roots of the saltstressed celery plants (Stoop and Pharr, 1994b). Presumably, the mannitol functions to partially alleviate the salt stress by functioning as an osmoticum or compatible solute.

Inhibition of growth resulting from salt and osmostress often is associated with accumulation of sugars throughout the stressed plant. Munns (1993) has argued that accumulation results simply from diminished sugar use as a result of reduced $\mathrm{C}$ demand by the growthinhibited sinks. As demonstrated below, the underlying mechanisms of mannitol accumulation in stressed celery are not passive. Mannitol accumulation in stressed celery involves specific regulation of mannitol synthesizing and catabolizing enzymes, resulting in an increase in mannitol concentration. For example, in leaves of salt-stressed celery, more photosynthetic ${ }^{14} \mathrm{CO}_{2}$ was incorporated into mannitol than into sucrose, and incorporation into mannitol at the expense of sucrose increased as the severity of salt stress increased (Everard et al., 1994). The total capacity for mannitol biosynthesis apparently increased in 
stressed celery leaves. In leaves of celery plants irrigated with $300 \mathrm{~mm}$ $\mathrm{NaCl}, \mathrm{M}-6-\mathrm{PR}$ activity in mature leaves increased as much as two-fold above that of control plants (Everard et al., 1994). Thus, one underlying mechanism of mannitol accumulation in salt-stressed celery plants is enhanced photosynthetic mannitol biosynthesis resulting from increased M-6-PR activity in source leaves.

Our current interest in the potential role of mannitol as a stress metabolite is an outgrowth of studies in which we noted marked differences in the mannitol : sugars ratio in celery plants grown in various substrates and nutrient salt environments (Stoop and Pharr, 1994a). In this work, petioles from celery plants grown in a peat-based soilless mixture (Promix) had a mannitol : sugars ratio of $\approx 2.0$, whereas plants grown in the same greenhouse environment but in hydroponic culture had a mannitol : sucrose ratio of 4.0 or higher. Plants in the peat-based culture received fertilization weekly with a soluble fertilizer (EC $1.8 \mathrm{dS} \cdot \mathrm{m}^{-1}$ ). These plants were watered daily, resulting in considerable leaching of fertilizer salts from the container. Plants in hydroponic culture were grown in a fertilizer solution maintained at a constant E.C. of $2.7 \mathrm{dS} \cdot \mathrm{m}^{-1}$. Subsequently, celery plants were grown hydroponically at EC levels of 2.7 or $6.0 \mathrm{dS} \cdot \mathrm{m}^{-1}$. These differences in total salinity were obtained by varying all of the macronutrients simultaneously while maintaining constant micronutrient concentrations. Plants grown at the higher EC had a markedly higher mannitol concentration than those grown at lower EC, suggesting that the total salinity of the nutrient environment in fact might be the cause of the altered mannitol concentration.

In another study, celery plants were grown in hydroponic culture at five salinity levels achieved by varying total macronutrient concentrations (Stoop and Pharr, 1994b). The nutrient solutions ranged from EC 1.0 to $11.9 \mathrm{dS} \cdot \mathrm{m}^{-1}$. Plants at all salinity levels increased in fresh weight logarithmically during the 35 days of the experiment, but the relative growth rate (RGR) of plants decreased progressively as EC of the

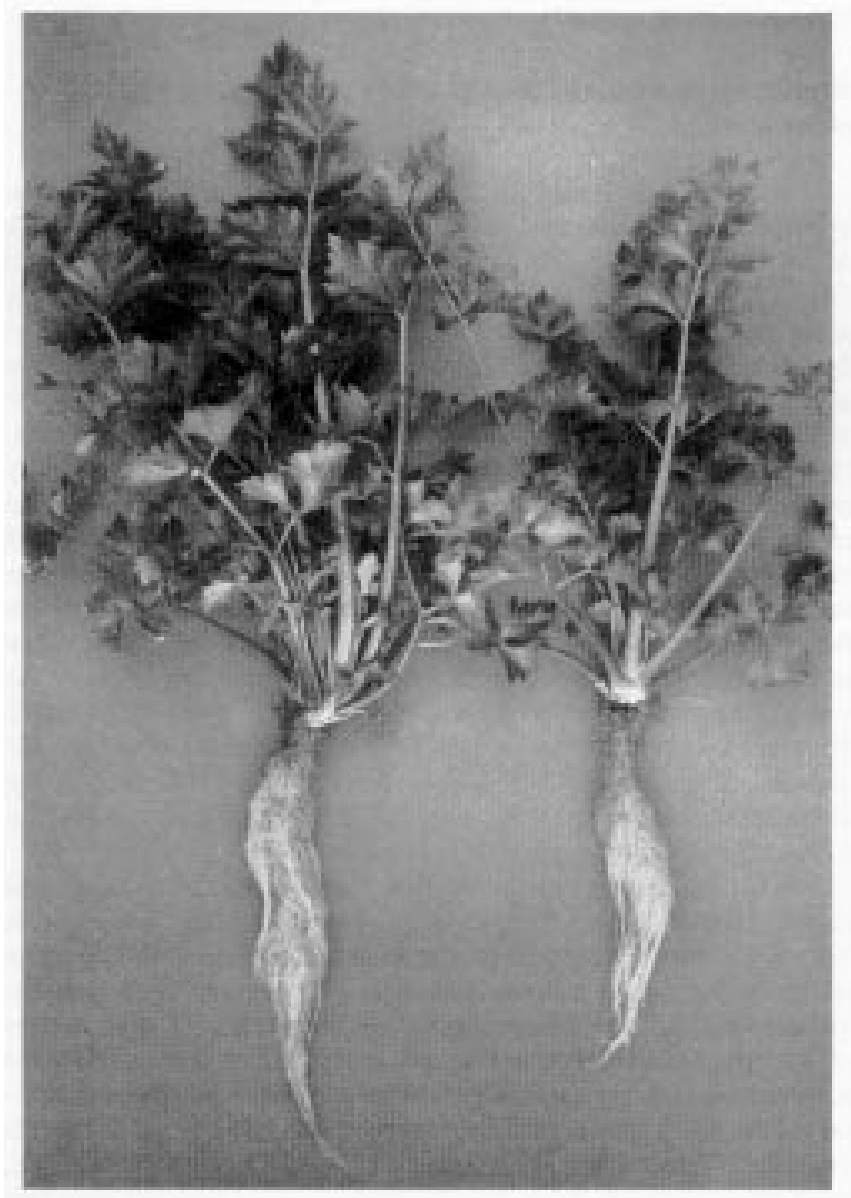

Fig. 4. Hydroponically grown celery plants. (left) Low macronutrient salinity $\left(\mathrm{EC}=1.7 \mathrm{dS} \cdot \mathrm{m}^{-1}\right) ;($ right $)$ high macronutrient salinity $\left(\mathrm{EC}=11.9 \mathrm{dS} \cdot \mathrm{m}^{-1}\right)$. Plants were grown for 35 days at respective macronutrient salinities. nutrient solution increased above $1.7 \mathrm{dS} \cdot \mathrm{m}^{-1}$. RGR, measured as fresh weight, of plants growing at EC $11.9 \mathrm{dS} \cdot \mathrm{m}^{-1}$ was about $70 \%$ of that for plants growing at EC $1.0 \mathrm{dS} \cdot \mathrm{m}^{-1}$. Other than the reduced size of the plants at the higher EC, there were no visual symptoms of stress, such as meristem, petiole, leaf, or root necrosis (Fig. 4).

Despite the reduction in fresh weight growth, plants from all treatments had equal dry weights, indicating that assimilatory ability of the plants was not reduced at increased nutrient salinity. This response constitutes strong tolerance to salinity in that the highest nutrient salinity was nearly $30 \%$ of that of seawater. The water content of all plant parts decreased progressively as salinity of the nutrient solutions increased. Analysis of macronutrient concentration $\left(\mathrm{NO}_{3}, \mathrm{P}\right.$, $\mathrm{K}, \mathrm{Ca}, \mathrm{Mg}$, and $\mathrm{Na}$ ) in the plants revealed that the increases in total nutrient concentrations in the nutrient solutions did not result in any increased nutrient content in any tissues of the celery plants when expressed on a dry-weight basis. Thus, celery responded to the treatments by nutrient exclusion with the result of osmotic stress.

In response to this stress, enzymatic adjustments apparently bring about increased production of mannitol in photosynthetic tissue by way of increased M-6-PR activity and conservation of mannitol by way of decreased MDH activity in sink tissues (Fig. 5). Mannitol concentration increased in all parts of the plants as EC of the nutrient solution increased (Stoop and Pharr, 1994). Sucrose concentration increased in leaves with increasing EC, but sucrose as well as hexose concentration was unchanged throughout the rest of the plant. M-6-PR activity from leaves doubled with increasing EC, confirming earlier observations made on NaCl-stressed plants (Everard et al., 1994). Leaf sucrose-P synthase activity also increased. The increase in mannitol concentration in response to excess salinity was not due solely to increased capacity for mannitol synthesis. In sink tissues, such as expanding leaves and petioles, and in root tips, MDH activity was strongly suppressed-near zero in root tips from plants grown at EC $11.9 \mathrm{dS} \cdot \mathrm{m}^{-1}$ (Stoop and Pharr, 1994). In these same sink tissues, the enzymatic capacity for sucrose degradation was unaffected by increasing salinity. Apparently, mannitol accumulation serves to alleviate stress. One apparent advantage for plants to make and translocate both sucrose and mannitol is that under stress they are able to accumulate mannitol as an osmoprotectant rather than using it as an assimilate for growth, while at the same time they still have sucrose available for assimilation and growth.

\section{SINK SSOURCE}

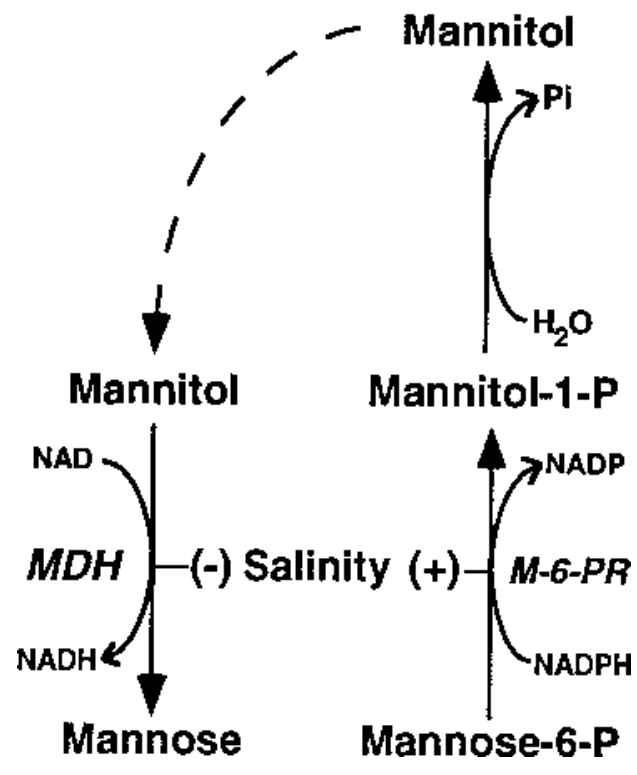

Fig. 5. Scheme depicting the coordinated regulation of mannitol synthesis in leaves and degradation in sinks leading to mannitol accumulation in stressed celery plants. 
Using antibodies raised against celery MDH, we recently reexamined extracts from roots of these macronutrient-stressed plants for changes in MDH activity (Fig. 6A) and MDH protein (Fig. 6B). MDH activity, expressed as per milligram of root protein (Fig. 5A) or per gram of fresh weight (Stoop and Pharr, 1994), decreased markedly in roots of celery plants with increasing salinity. We used a protein (western) blot of equal amounts of protein from roots of plants grown at the various levels of salinity (Fig. 6B). Clearly, the decreased MDH activity is specifically associated with decreased amounts of protein cross-reacting with our MDH antibodies. This is different from the proposed regulation of mannitol accumulation in the alga, Platymonas subcordiformis, in which activity of the algal mannitol dehydrogenase enzyme is inhibited directly by $\mathrm{NaCl}$ and, thus, promotes mannitol accumulation (Richter and Kirst, 1987). Sodium chloride, even at $0.5 \mathrm{M}$, was not inhibitory to in vitro activity assays of MDH purified from celery suspension culture cells (unpublished). The mechanisms of regulation of enzymes from algae and celery to achieve the same end result, i.e., mannitol accumulation, are obviously very different. In summary, mannitol accumulation in response to stress appears to be the result of an up-regulation of mannitol biosynthesis in photosynthetic tissues and a down-regulation of mannitol catabolism in sink tissues (Fig. 5).

\section{PROSPECTS}

Osmotic stress, resulting from either salinity or drought, is of substantial concern in greenhouse and field cultivation of diverse horticultural crops. Given the potential for osmoprotection and increased yield provided by mannitol metabolism, engineering plants
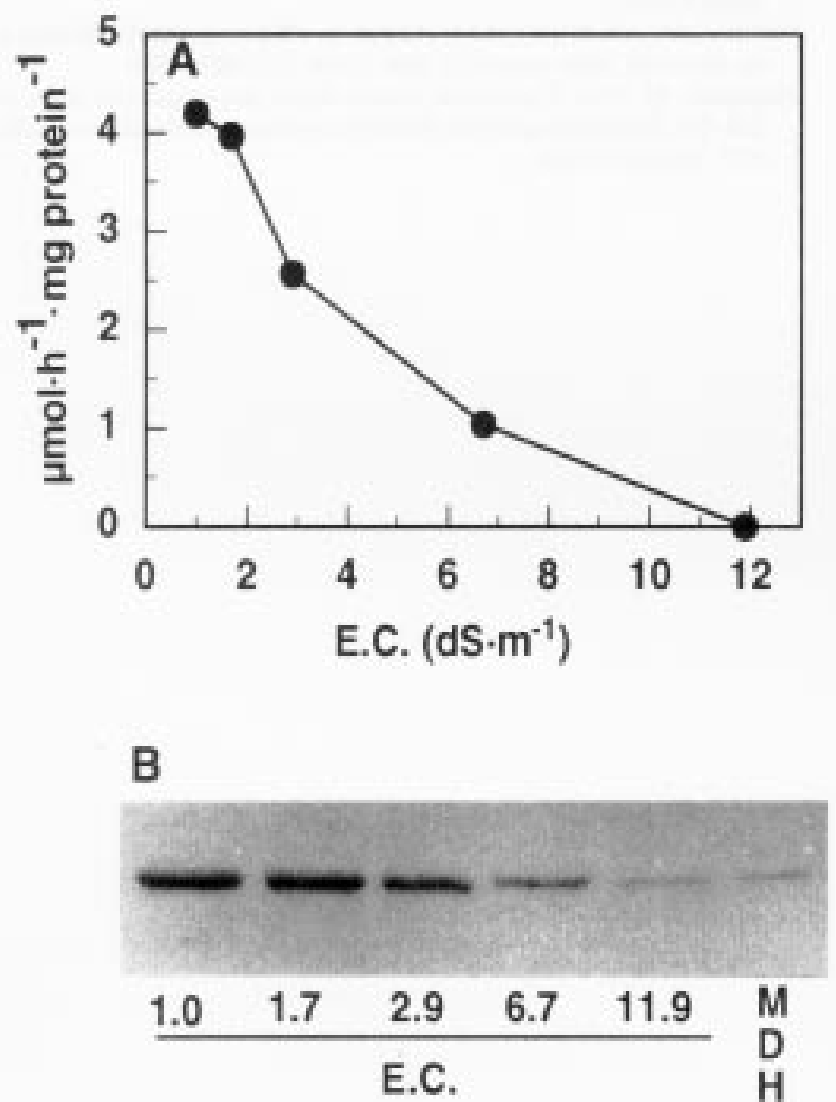

Fig. 6. (A) Mannitol dehydrogenase activity (units of enzyme activity/milligram of total root protein) in extracts from young roots of celery plants grown for 35 days at different macronutrient salinities (of the nutrient solutions in which the celery plants were grown) ranging from EC 1.0 to $11.9 \mathrm{dS} \cdot \mathrm{m}^{-1}$. (B) Western blot of SDS polyacrylamide gel of $30 \mu \mathrm{g}$ of total protein from each of the samples in (A). Lane labeled "(MDH)" is $0.1 \mu \mathrm{g}$ of mannitol dehydrogenase purified from mannitol-grown celery suspension culture cells. Blots were challenged with rabbit MDH-specific antibodies and then with goat-anti-rabbit antibody linked to alkaline phosphatase for visualization. with this capability is a compelling goal. While the protective role of introduced mannitol synthesis has been demonstrated (Tarczynski et al., 1993), plant growth might benefit substantially from the ability to switch from accumulation of mannitol under stress conditions to use of transported mannitol under nonstress conditions. The introduction of the genes for mannitol use, as well as mannitol synthesis, could provide this capability.

In pursuit of this goal, we have begun isolating and characterizing the MDHcDNA from celery cells. Cells cultured in mannitol-containing medium show a substantial increase in MDH activity upon transfer to fresh mannitol-containing medium. This increase in activity appears to peak between 3 and 4 days posttransfer, so poly $\mathrm{A}^{+}$RNA isolated from cells 3 days posttransfer was used for construction of a cDNA library. The resulting cDNAs were ligated into the new SPELL OUT BRL expression vector $\lambda$-ZIPLOX, and phage-containing DNA specifically encoding MDH protein were detected using an antibody raised against gel-purified MDH. Bacteria containing excised plasmids with cDNAs encoding proteins cross-reactive with our MDH antibody were grown in inducing liquid medium, and the resulting induced proteins were verified by western blot analysis to be of appropriate size (not shown). Isolated plasmid DNA was assessed by restriction analysis and clones containing putative full-length $\mathrm{MDH}$ cDNA inserts were selected for DNA sequence analysis. Peptide sequence data obtained from analysis of purified MDH will be used to verify the identity of these clones.

Once verified, the utility of these clones will be several-fold. These sequences could be used immediately to analyze the response of MDH transcript accumulation to osmotic stress, drought, and available $\mathrm{C}$ source. Use of the cDNA to isolate MDH genomic sequences would allow the characterization of the control intermediates in this response, e.g., is this a direct stress response or a response to the accumulation of other stress-induced factors/metabolites.

Perhaps of more immediate interest, this sequence affords a pathway into the detailed analysis of the physiology and biochemistry of mannitol metabolism. In initial experiments, antisense genes (with the MDH sequences in reverse orientation) will be constructed to "turn off" MDH expression in celery cell suspension cultures. These transformed cells will be analyzed to see how this affects their ability to grow on mannitol. This ability to target a specific metabolic nexus is a powerful tool in determining biochemical/metabolic function. Analysis of the effect of antisense constructs in transgenic plants would provide additional insight into the role of $\mathrm{MDH}$ in overall plant growth and stress response.

The mannitol-catabolizing enzyme, $\mathrm{MDH}$, as detailed above, is a monomer and appears to require no special cofactors. Initial experiments in our laboratory indicate that changes in amount of MDH protein in response to osmotic stress parallel changes in amount of MDH transcript (not shown). Thus, manipulation of MDH activity in planta should be straightforward. Once characterized, the MDH sequence, fused to an appropriate promoter, will be transformed into tobacco plants already containing the mannitol-synthesizing enzyme from E. coli (Tarczynski et al., 1992). The effect of this coupled system on photoassimilative capability, growth, and salt tolerance then could be assessed. Ultimately, the isolation of the celery (or other plant) mannitol biosynthetic gene(s) would be desirable. Introduction of a cassette or cassettes containing these two genes with their own promoters that are responsive to salt-stress signals into horticultural crops not already possessing mannitol metabolic/catabolic pathways could result in the production of crops with increased salt tolerance and photoassimilative capability.

\section{Literature Cited}

Bieleski, R.L. 1982. Sugar alcohols, p. 158-192. In: F.A. Loewus and W. Tanner (eds.). Plant carbohydrates I. Intracellular carbohydrates. Encyclo. Plant Physiol. vol. 13A. New series. Springer-Verlag, New York.

Clipson, N.J.W., M.A. Hajibagheri, and D.H. Jennings. 1990. Ion compartmentation in the marine fungus Dendryphiella salina in response to salinity: X-ray microanalysis. J. Expt. Bot. 41:199-202.

Davis, J.M., J.K. Fellman, and W.H. Loescher. 1988. Biosynthesis of sucrose and mannitol as a function of leaf age in celery (Apium graveolens L.). Plant Physiol. 86:129-133. 
Everard, J.D., V.R. Franceschi, and W.H. Loescher. 1993a. Mannose-6phosphate reductase, a key enzyme in photoassimilate partitioning, is abundant and located in the cytosol of photosynthetically active cells of celery (Apium graveolens L.) source leaves. Plant Physiol. 102:345-356.

Everard, J.D., R. Gucci, S.C. Kann, J.A. Flore, and W.H. Loescher. 1994. Gas exchange and carbon partitioning in the leaves of celery (Apium graveolenx L.) at various levels of root zone salinity. Plant Physiol. 106:281-292.

Everard, J.D., S.C. Kann, and W.H. Loescher. 1992. Investigations into the salt tolerance of the mannitol producer celery. Plant Physiol. 99(suppl.):28.

Fellman, J.K. and W.H. Loescher. 1987. Comparative studies of sucrose and mannitol utilization in celery (Apium graveolens). Physiol. Plant. 69:337341.

Fox, T.C., R.A. Kennedy, and W.H. Loescher. 1986. Developmental changes in photosynthetic gas exchange in the polyol-synthesizing species, Apium graveolens L. (celery). Plant Physiol. 82:307-311.

Greenway, H. and R. Munns. 1980. Mechanisms of salt tolerance in nonhalophytes. Annu. Rev. Plant Physiol. 31:149-190.

Herold, A. and D.H. Lewis. 1977. Mannose and green plants: Occurrence, physiology and metabolism, and use as a tool to study the role of orthophosphate. New Phytol. 79:1-40.

Jennings, D.H. 1984. Polyol metabolism in fungi. Adv. Microbiol. Physiol. 25:149-193.

Kann, S.C., J.D. Everard, and W.H. Loescher. 1993. Growth, salt tolerance and mannitol accumulation in celery. Plant Physiol. 28:126. (Abstr.)

Keller, F. and P. Matile. 1989. Storage of sugars and mannitol in petioles of celery leaves. New Phytol. 113:291-299.

Kirst, G.O. 1989. Salinity tolerance of eukaryotic marine algae. Annu. Rev. Plant Physiol. Plant Mol. Biol. 40:21-53.

Lewis, D.H. 1984. Physiology and metabolism of alditols, p. 143-184. In: D.H. Lewis (ed.). Storage carbohydrates in vascular plants. Cambridge Univ. Press, Cambridge, England.

Loescher, W.H. 1987. Physiology and metabolism of sugar alcohols in higher plants. Physiol. Plant. 70:553-557.

Loescher, W.H., R.H. Tyson, J.D. Everard, R.J. Redgwell, and R.L. Bieleski. 1992. Mannitol synthesis in higher plants. Evidence for the role and characterization of a NADPH-dependent mannose-6-phosphate reductase. Plant Physiol. 98:1396-1402.

Munns, R. 1993. Physiological processes limiting plant growth in saline soils:
Some dogmas and hypotheses. Plant Cell Environ. 16:15-24.

Richter, D.F.E. and G.O. Kirst. 1987. d-mannitol dehydrogenase and Dmannitol-1-phosphate dehydrogenase in Platymonas subcordiformis: Some characteristics and their role in osmotic adaptation. Planta 170:528-534.

Rumpho, M.E., G.E. Edwards, and W.H. Loescher. 1983. A pathway for photosynthetic carbon flow to mannitol in celery leaves. Activity and localization of key enzymes. Plant Physiol. 73:869-873.

Schobert, B. 1977. Is there an osmotic regulatory mechanism in algae and higher plants? J. Theor. Biol. 68:17-26.

Smirnoff, N. and Q.J. Cumbes. 1989. Hydroxyl radical scavenging activity of compatible solutes. Phytochemistry 28:1057-1060.

Stitt, M. 1986 Limitation of photosynthesis by carbon metabolism. Plant Physiol. 81:1115-1122.

Stoop, J.M.H. 1993. Mannitol catabolism in celery (Apium graveolens L.): Role and characterization of a novel mannitol 1-oxidoreductase. PhD Diss., North Carolina State Univ., Raleigh.

Stoop, J.M.H. and D.M. Pharr. 1992. Partial purification and characterization of mannitol: Mannose 1-oxidoreductase from celeriac (Apium graveolens var. rapaceum) roots. Arch. Biochem. Biophys. 298:612-619.

Stoop, J.M.H. and D.M. Pharr. 1993. Effect of different carbon sources on relative growth rate, internal carbohydrates, and mannitol 1-oxidoreductase activity in celery suspension cultures. Plant Physiol. 103:1001-1008.

Stoop, J.M.H. and D.M. Pharr. 1994a. Growth substrate and nutrient salt environment alter mannitol to hexose partitioning in celery petioles. J. Amer. Soc. Hort. Sci. 119:237-242.

Stoop, J.M.H. and D.M. Pharr. 1994b. Mannitol metabolism in celery stressed by excess macronutrients. Plant Physiol. 106:503-511.

Tarczynski, M.C., R.G. Jensen, and H.J. Bohnert. 1992. Expression of a bacterial $m t l D$ gene in transgenic tobacco leads to production and accumulation of mannitol. Proc. Natl. Acad. Sci. USA 89:2600-2604.

Tarczynski, M.C., R.G. Jensen, and H.J. Bohnert. 1993. Salt protection of transgenic tobacco by production of the osmolyte mannitol. Science 259:508-510.

Vorhaben, J.E., J.F. Scott, and J.W. Campbell. 1980. D-mannitol oxidation in the land snail, Helix aspersa. J. Biol. Chem. 255:1950-1955.

Yamaguchi, M. 1983. Umbellifers: Carrot, celery, and continental herbs, p. 239-251. In: World vegetables: Principles, production and nutritive values. AVI, Westport, Conn. 